\title{
A FORMAÇÃO DOS PROFESSORES MINISTRANTES DE UM PROGRAMA DE ENSINO MÉDIO COM MEDIAÇÃO TECNOLÓGICA: os aspectos metodológicos no caso de Rondônia
}

\author{
Daniela Tissuya Silva Toda? \\ Rosângela de Fátima Cavalcante França²
}

\section{RESUMO}

O programa Ensino Médio com Mediação Tecnológica (EMMTEC) foi desenvolvido para atender ao alunado residente nas áreas de floresta, agropecuária, ribeirinha, pesqueira, extrativista, quilombola e indígena de todos os municípios rondonienses. O programa teve início em 2016, com $01^{\circ}$ ano do Ensino Médio, prevendo implementação gradual dos demais anos. O EMMTEC possui características similares aos cursos da modalidade de Educação a Distância: as aulas são regidas por professores ministrantes, em Porto Velho, e transmitidas em tempo real para as escolas polo. Nesse contexo, a presente pesquisa - que tem caráter empírico e descritivo, com abordagem qualitativa - foi realizada entre julho de 2017 e março de 2018, objetivando analisar em que medida a formação docente dos professores ministrantes do EMMTEC garante o desenvolvimento dos aspectos metodológicos, tecnológicos e de autonomia. Apresenta-se, aqui, o recorte da pesquisa no que tange aos aspectos metodológicos. Como instrumento de coleta de dados, empregou-se a entrevista semiestruturada. Para a análise dos dados, utilizou-se a técnica categorial temática de análise de conteúdo. Os sujeitos foram escolhidos aleatoriamente, preservando-se a identidade. Os resultados apontam que os professores tiveram uma formação centrada no desempenho em estúdio de gravação, excluindo-se os aspectos metodológicos pertinentes ao ensino com mediação tecnológica, em contraposição ao que é preconizado pelos pesquisadores da área.

Palavras-chave: Formação docente. Ensino Médio com mediação tecnológica. Aspectos metodológicos.

\footnotetext{
1 Mestrado em Educação. Professora do Instituto Federal de Educação, Ciência e Tecnologia de Rondônia, Porto Velho, Rondônia, Brasil. Orcid iD: https://orcid.org/0000-00033175-0966. E-mail: daniela.toda@ifro.edu.br

2 Doutorado em Educação Escolar. Professora da Universidade Federal de Rondônia, Porto Velho, Rondônia, Brasil. Orcid iD: https://orcid.org/0000-0003-2301-7000. E-mail: rosangela.franca@unir.br
} 


\title{
THE TRAINING OF MINISTRANT TEACHERS IN A HIGH SCHOOL PROGRAM WITH TECHNOLOGICAL MEDIATION:
}

\author{
the methodological aspects in the case of Rondônia
}

\begin{abstract}
The High School with Technological Mediation program (EMMTEC) was developed to assist students residing in the forest, agriculture, riverside, fishing, extractive, quilombola and indigenous areas of all the municipalities in Rondônia. This program started in 2016, with the 1st year of High School, foreseeing the gradual implementation of the other years. EMMTEC has similar characteristics to Distance Education modality courses: classes are conducted by teachers, in Porto Velho, and transmitted in real time to the polo schools. In this context, the present research which has an empirical and descriptive character, with a qualitative approach - was carried out between July 2017 and March 2018, aiming to analyze to what extent the formation of the EMMTEC teachers guarantees the development of methodological, technological and autonomy aspects. This text presents a research clipping in terms of methodological aspects. As a data collection instrument, semistructured interviews were used and, for data analysis, the thematic categorical technique of content. The subjects were randomly chosen, preserving their identity. The results show that the teachers had a training centered on performance in a recording studio, excluding the methodological aspects pertinent to teaching with technological mediation, in contrast to what is recommended by researchers in the area.
\end{abstract}

Keywords: Teacher training. High school with technological mediation. Methodological aspects.

\section{LA FORMACIÓN DE MAESTROS MINISTRANTES DE UN PROGRAMA DE ESCUELA SECUNDARIA CON MEDIACIÓN TECNOLÓGICA:}

los aspectos metodológicos en el caso de Rondônia

\section{RESUMEN}

El Programa Escuela Secundaria con Mediación Tecnológica (EMMTEC) fue desarrollado para atender a los estudiantes residentes en las áreas forestal, agrícola, ribereña, pesquera, extractiva, quilombola e indígena de todos los municipios de Rondônia. El Programa se inició en 2016, con el ler año del curso secundario, previendo la implementación paulatina de los demás años. EMMTEC tiene características similares a los cursos de la modalidad de Educación a Distancia: las clases son impartidas por profesores docentes en Porto Velho, y transmitidas en tiempo real a las escuelas pólo. En este contexto, la presente investigación - que tiene un carácter empírico y descriptivo, con enfoque cualitativo - se realizó entre julio de 2017 y marzo de 2018, con el objetivo de analizar en qué medida la formación docente de los profesores de la EMMTEC garantiza el desarrollo de los aspectos metodológicos, tecnológicos y de la autonomía. Aquí, la investigación se presenta en términos de los aspectos metodológicos. Como instrumento de 
recolección de datos se utilizaron entrevistas semiestructuradas. Para el análisis de datos se utilizó la técnica categórica temática de análisis de contenido. Los sujetos fueron elegidos al azar, preservando su identidad. Los resultados muestran que los docentes tuvieron una formación centrada en la actuación en un estudio de grabación, excluyendo los aspectos metodológicos pertinentes a la docencia con mediación tecnológica, en contraposición a lo recomendado por los investigadores del área.

Palabras clave: Formación docente. Escuela Secundaria con mediación tecnológica. Aspectos metodológicos.

\section{INTRODUÇÃO}

O estado de Rondônia, localizado na Região Norte do Brasil, por meio da Secretaria de Estado de Educação de Rondônia (SEDUC-RO), implementou o programa Ensino Médio com Mediação Tecnológica (EMMTEC), que começou a funcionar em 2016, ofertando essa etapa do Ensino Básico para o alunado do campo, compreendido como os residentes em espaços da floresta, agropecuária, ribeirinhos, pesqueiros, extrativistas, quilombolas e indígenas de todos os municípios rondonienses (RONDÔNIA, 2016).

O EMMTEC foi apresentado como uma alternativa administrativopedagógica para assegurar o atendimento desses alunos, em face às dimensões territoriais e às dificuldades geográficas de acesso na Região Amazônica, na qual Rondônia se insere, e também para suprir o déficit de professores habilitados atuantes na esfera estadual, podendo ser ofertado também em áreas urbanas que apresentam tal problemática (RONDÔNIA, 2016).

Baseado no Ensino Médio Presencial com Mediação Tecnológica (EMPMT) do estado do Amazonas, o EMMTEC, em Rondônia, por meio da mediação tecnológica, oferece aulas ministradas por docentes formados nas áreas de conhecimento do componente curricular, transmitidas ao vivo, via satélite, ao mesmo tempo em que são gravadas para serem disponibilizadas na internet (RONDÔNIA, 2016). Esses docentes são denominados pela SEDUC-RO como "professores ministrantes". Nas escolas das comunidades que recebem o programa, há docentes licenciados em 
diversas áreas do conhecimento, denominados "professores presenciais", que prestam assistência aos alunos e aos professores ministrantes.

Essa similaridade do programa com a Educação a Distância (EaD) em que há distância geográfica entre professores e alunos e o uso de recursos tecnológicos para mediar os processos de ensino e aprendizagem produziu inquietações e indagações sobre a formação de professores para o ensino com mediação tecnológica. Ao aprofundarmos o estudo sobre o projeto do EMMTEC, soubemos que consta a previsão de um curso de formação para os professores ministrantes.

Assim, propusemo-nos pesquisar sobre a formação continuada dos professores ministrantes desse programa, no que se refere aos aspectos metodológicos, tecnológicos e de autonomia, visando contribuir com as discussões sobre a formação docente para o ensino nessa modalidade. Apresentamos, neste texto, o recorte da pesquisa que abrange os aspectos metodológicos da formação desses professores. Os dados foram coletados por meio da entrevista semiestruturada e gravada, e analisados com a técnica categorial temática de análise de conteúdo, conforme a proposta de Bardin (2011).

Além desta introdução, este texto contém as seguintes seções: Formação continuada de professores e ensino com mediação tecnológica: perspectivas teóricas; formação de professores para EaD; o programa EMMTEC; os caminhos metodológicos percorridos na pesquisa; formação metodológica - análise de dados; considerações finais; e, por fim, as referências.

\section{FORMAÇÃO CONTINUADA DE PROFESSORES E ENSINO COM MEDIAÇÃO TECNOLÓGICA: PERSPECTIVAS TEÓRICAS}

O aperfeiçoamento dos conhecimentos e práticas pertinentes ao exercício da docência, em continuidade à formação inicial, ocorre no processo de formação continuada. Nas últimas décadas, essa formação tem sido tema de discussões e proposições de diferentes tendências, dentre 
as quais podemos destacar: a formação centrada na escola, a formação do professor reflexivo e a formação por meio dos saberes docentes.

A perspectiva da formação continuada centrada na escola, apresentada neste trabalho, tem como base os escritos de Imbernón (2010), que defende não ser possivel separar a formação do contexto do trabalho, uma vez que a formação continuada de professores perpassa pela situação em que estes estão inseridos: contexto político-social, situação de trabalho, normativas e estrutura da instituição e situação da educação em todos os níveis escolares.

Os programas de formação continuada de professores, com cursos ministrados por sujeitos alheios à realidade da escola ou do professor, tornam-se inócuos, posto que "tudo que se explica não serve para todos e nem se aplica a todos os lugares. O contexto condicionará as práticas formadoras, bem com a sua repercussão nos professores, e, sem dúvida, na inovação e na mudança" (IMBERNÓN, 2010, p. 9).

A escola - com o seu contexto próprio, que varia de acordo com o tempo e o espaço - é o local onde o professor está inserido e, portanto, constitui-se como lugar propício para a formação continuada de professores, desde que envolva os profissionais da escola no desenvolvimento dos programas de formação. A esse respeito, Candau (2001, p. 58) afirma:

Trata-se de trabalhar com o corpo docente de uma determinada instituição, favorecendo processos coletivos de reflexão e intervenção na prática pedagógica concreta, de oferecer espaços e tempos institucionalizados nesta perspectiva, de criar sistemas de incentivo à sistematização das práticas pedagógicas dos professores e à sua socialização, de ressituar 0 trabalho de supervisão/orientação nessa perspectiva.

Assim, a escola não é apenas o local físico para a formação continuada, mas o ambiente que proporciona o diálogo e a discussão das necessidades entre professores e gestores, para o desenvolvimento da formação continuada.

A perspectiva de formação profissional reflexiva é discutida por Donald Schön (2000), na perspectiva de que os problemas da prática do mundo real 
não se apresentam aos profissionais como estruturas bem delineadas, mas, ao contrário, são caóticos e indeterminados, não bastando os conhecimentos técnicos adquiridos na formação profissional para resolvê-los. Essa reflexão também é encontrada, segundo afirma o autor, em uma reclamação de críticos profissionais de que as áreas mais importantes da prática profissional se encontram além das fronteiras convencionais da competência profissional. O que os aspirantes mais necessitam, segundo ele, é aprender a prática profissional, algo que as escolas profissionais têm dificuldades em ensinar.

O pensamento de Schön (2000) explicita a preocupação sobre o distanciamento entre a teoria e a prática no ensino profissional, bem como sobre a formação - que não considera aspectos além dos técnicos - para a resolução dos problemas encontrados no cotidiano da profissão. O autor defende o ensino prático reflexivo, no qual o estudante e o professor criam paralelismos, um com a prática do outro, dentro e fora da aula, passíveis de serem observados e demonstrados na ação, constituindo o "conhecer-naação" e o ensino prático reflexivo.

Ao discutir a prática reflexiva na formação do professor, Pimenta (2002) pondera que é necessário considerar o contexto no qual ele está inserido (político, institucional e teórico-metodológico), para que não haja uma individualização do professor e ações descontextualizadas, pertinentes a apenas uma situação específica, incapazes de transformar as práticas educativas. A prática reflexiva é compreendida, portanto, como a análise crítica dos professores sobre a prática realizada, relacionando os resultados obtidos com o aporte teórico.

Sob a perspectiva de saberes docentes, a formação continuada se baseia na impossiblidade de dissociação dos saberes com o contexto de trabalho, pois eles estão relacionados ao sujeito, sua identidade, suas experiências de vida, sua história profissional e sua relação com os colegas de trabalho e os alunos (TARDIF, 2014). Esses conhecimentos são plurais, constituídos de experiências pessoais e profissionais. Tardif (2014) classifica os saberes docentes como: (i) saberes profissionais - transmitidos pelas 
instituições formadoras de professores; (ii) saberes disciplinares - produzidos pelas ciências e validados pela sociedade, a partir do momento em que são escolhidos para serem repassados; (iii) saberes curriculares - correspondem aos discursos, objetivos, conteúdos e métodos, a partir dos quais a escola seleciona, define e apresenta para a formação de cultura erudita; e (iv) saberes experienciais - advindos das vivências individuais e coletivas, em que os professores selecionam quais saberes podem ser dispensados.

Considerando as abordagens teóricas de formação continuada de professores, bem como a necessidade de que as políticas de formação docente contribuam para um novo perfil de professor (CARVALHO; DAMASCENO; MOURA, 2019) e as mudanças geradas pela inserção das tecnologias, é imprescindível contemplar a formação para o uso de Tecnologias da Informação e Comunicação (TIC) na educação, devido a sua expansão das últimas décadas. As TIC contemplam recursos tecnológicos digitais, elementos de multimídia e hipertextos, disponíveis em suportes físicos ou não, podendo ser utilizadas em materiais didáticos, atividades lúdicas e avaliações, para propiciar experiências cognitivas, exploratórias ou comportamentais (AZEVEDO, 2009).

Libâneo (2007) afirma que o professor é indispensável para a criação de condições afetivas e cognitivas que auxiliarão o aluno a atribuir significados às mensagens recebidas das mídias e multimídias. Assim, é necessário um novo professor que seja, segundo o autor,

[...] capaz de ajustar sua didática às novas realidades da sociedade, do conhecimento, do aluno, dos meios de comunicação. O novo professor precisaria, no mínimo, de adquirir sólida cultura geral, capacidade de aprender a aprender, competência para saber agir na sala de aula, habilidades comunicativas, domínio da linguagem informacional e dos meios de informação, habilidade de articular as aulas com as mídias e multimídias (LIBÂNNEO, 2007, p. 28, grifo nosso).

A incorporação de recursos tecnológicos na educação requer, portanto, uma formação docente consistente, para que o uso desses recursos seja significativo, pertinente e alinhado aos processos de ensino, de modo a não ser esvaziado de objetivo. Pesquisadores da área de EaD, como 
Pallof e Pratt (2015) e Kenski (2008; 2012), possuem uma visão semelhante no tocante à formação de professores para essa modalidade.

Assim, as semelhanças do EMMTEC com a EaD nos levaram a estudar os pressupostos teóricos da formação docente para atuação nessa modalidade de ensino, cuja possibilidade de oferta é baseada no uso de tecnologias, sejam analógicas ou digitais. As questões que permeiam a formação de professores para a EaD serão apresentadas na subseção a seguir.

\title{
Formação de professores para EaD
}

O preparo de professores para atuar na EaD requer a formação para o uso de tecnologias e metodologias diferenciadas, condizentes com os cursos ofertados on-line, e aplicadas à realidade, pois o domínio de utilização de um sistema para gerenciamento de curso a distância não significa que os professores compreendam como ministrá-lo de forma eficaz (PALLOF; PRATT, 2015). Assim, na transição do ensino presencial para a EaD, de acordo com os autores mencionados,

\begin{abstract}
Não se pode esperar que os docentes saibam intuitivamente como projetar e disponibilizar um curso on-line eficaz. Embora alguns cursos e programas sobre o uso de tecnologia na educação estejam surgindo em instituições de ensino superior e estejam disponíveis aos professores em capacitação, os docentes mais experientes não foram expostos às técnicas e aos métodos necessários para serem bem-sucedidos no universo on-line (PALLOF; PRATT, 2015, p. 38).
\end{abstract}

Pallof e Pratt (2015) criticam a ênfase que os programas de capacitação de professores dão para o uso de TIC e a pouca atenção destinada às questões metodológicas que permeiam os cursos ofertados em plataformas digitais, considerando que o fato de os professores aprenderem a operacionalizar as ferramentas tecnológicas não garante que eles saibam aplicá-las adequadamente nos processos de ensino e aprendizagem da EaD, os quais possuem suas peculiaridades. 
Kenski (2008) assevera que a transposição das práticas didáticas do ensino presencial para a EaD, sem considerar as diferenças que essas duas modalidades possuem, gera problemas. Na análise do autor,

\begin{abstract}
Por melhor que seja a transmissão dessas aulas, o procedimento é da tradicional aula expositiva, baseada na performance do professor e - que desconhece os interesses, as necessidades e as especificidades dos alunos. Todos esses procedimentos estão comprometidos com o ensino e o desempenho do professor. Esquecem, portanto, a real finalidade da educação, que é a de oferecer as melhores condições para que ocorra a aprendizagem de todos os alunos. Na maioria das vezes, esses profissionais do ensino estão mais preocupados em usar as tecnologias que têm a sua disposição para "passar o conteúdo", sem se preocupar com o aluno, aquele que precisa aprender (KENSKI, 2008, p. 57).
\end{abstract}

A formação de professores, portanto, não pode se limitar à capacitação tecnológica para o uso dos recursos de mediação dos processos de ensino e aprendizagem. É necessário que a formação abranja aspectos metodológicos de práticas didáticas que proporcionem dinamismo, interatividade e dialogicidade entre todos os participantes, favorecendo o encurtamento da distância entre os sujeitos, para uma aprendizagem significativa.

\title{
O PROGRAMA EMMTEC
}

O EMMTEC foi desenvolvido com o objetivo de cumprir a exigência constitucional de oferta universal do Ensino Médio e, por meio dele, alcançar o alunado do campo - compreendido nas áreas de floresta, agropecuária, ribeirinha, quilombola e indígena - e também às áreas de difícil acesso, como as alagadas e unidades de conservação. Excepcionalmente, o programa pode ser estendido às escolas de área urbana, caso haja déficit de professores habilitados nos componentes curriculares dessa etapa do ensino básico (RONDÔNIA, 2016).

As aulas são gravadas no turno vespertino, em estúdio sediado em Porto Velho, capital do estado, enquanto são transmitidas ao vivo, via satélite, para as escolas participantes do programa, sendo exigida dos 
alunos a frequência mínima de $75 \%$ como um dos requisitos para aprovação. A presença dos alunos é contabilizada pelos professores presenciais que, além de acompanhar os alunos durante a transmissão e registrar a frequência, têm como atribuições: mediar a comunicação entre professores ministrantes e alunos, que ocorre via chat durante a transmissão, aplicar e corrigir avaliações (RONDÔNIA, 2016).

Em adição às funções já mencionadas, o projeto do EMMTEC prevê as seguintes: coordenador pedagógico de estúdio, coordenador da Coordenadoria Regional de Educação (CRE) e coordenador pedagógico da SEDUC-RO. No que tange aos professores ministrantes, são designados dois para cada componente curricular, concursados e efetivos, que cumpram os seguintes requisitos: formação acadêmica mínima na área de conhecimento específico do componente curricular que irá ministrar; interesse em participar do programa; estar aberto a mudanças e às novas formas de ensinar e aprender; ter interesse na idiossincrasia das comunidades campestres de Rondônia; ser comprometido, responsável e criativo (RONDÔNIA, 2016).

Os professores ministrantes são responsáveis por: elaboração de Plano de Operacionalização do componente curricular; encaminhamento de Plano de Operacionalização às coordenações pedagógicas do estúdio e da SEDUC-RO; elaboração de avaliações; elaboração de Plano de Estudo para recuperação paralela; comparecimento nos eventos de formação de professores presenciais; elaboração das dinâmicas locais (DL); participação em treinamento para o estúdio; participação das avaliações didáticopedagógicas do curso; ministração de aulas em estúdio, com transmissão em tempo real; elaboração de soluções para eventuais problemas relacionados ao componente curricular do qual é responsável (RONDÔNIA, 2016).

Diante das atribuições elencadas, foi prevista uma capacitação para os professores ministrantes, com oitenta horas, denominada Didática no Ensino Presencial Mediado, com o seguinte conteúdo programático: 
- Mídias, parceiras do processo pedagógico;

- Histórico da Educação a Distância;

- As competências do professor frente às mudanças: mediador do diálogo pedagógico;

- Planejamento de aula, o exercício de fazer diferente;

- A seleção e produção de recursos da comunicação;

- A ênfase na contextualização;

- O olhar sobre a transdisciplinaridade;

- Funcionamento da Plataforma Tecnológica;

- Desenho do sistema e funcionamento;

- A preparação do educador-comunicador;

- Potencializando os recursos pessoais: expressão corporal, voz e presença física;

- Desempenho na sala de aula mediada;

- Oficina;

- Vivenciando uma aula (RONDÔNIA, 2016, p. 57).

Percebemos que a capacitação prevista para os professores ministrantes contempla os aspectos tecnológicos (como o desenho e funcionamento do sistema e da plataforma tecnológica) e os aspectos metodológicos, tais como o planejamento da aula e o professor educadorcomunicador. Segundo informações extraídas da entrevista semiestruturada utilizada nesta pesquisa, verificamos que, realmente, a SEDUC-RO ofertou uma capacitação para os professores que atuam em estúdio.

Em 2017, O EMMTEC abrangeu 17 CRE, com 122 escolas, localizadas em uma terra indígena, 33 municípios e 31 distritos, atendendo a 4.366 alunos. Esses números demonstram o grande alcance do programa, mesmo ainda em fase de implementação.

Na próxima seção, descrevemos os passos metodológicos realizados durante este estudo.

\section{OS CAMINHOS METODOLÓGICOS PERCORRIDOS NA PESQUISA}

Apresentamos um recorte de pesquisa realizada, cuja abordagem é qualitativa, considerando-se as minúcias descritivas em relação às pessoas, locais e conversas, de difícil tratamento estatístico, conforme explicam Bodgan e Biklen (1994).

A investigação é do tipo descritiva, pois os dados recolhidos são palavras e não números (BOGDAN; BIKLEN, 1994). Utilizamos a entrevista semiestruturada como instrumento de coleta, visto que não há nela um 
ordenamento rígido das questões, o entrevistado discorre sobre o tema proposto baseado nas informações que possui e, havendo um clima de estímulo e aceitação mútua, as informações fluem livremente, permitindo também correções, esclarecimentos e adaptações (LÜDKE; ANDRÉ, 1986). As entrevistas foram gravadas, para auxiliar no processo de análise e evitar a perda de dados.

Apresentamo-nos à SEDUC-RO, pessoalmente e por carta, solicitando autorização para realizar a pesquisa, sendo-nos concedida a carta de anvência pela referida instituição. Em seguida, submetemos o projeto de pesquisa ao Comitê de Ética em Pesquisa (CEP), que emitiu o Parecer Consubstanciado, aprovando nosso projeto. De posse desse Parecer, retornamos à SEDUC-RO, a fim de explicar aos sujeitos o objetivo da pesquisa e colher as assinaturas no Termo de Consentimento Livre e Esclarecido daqueles que assentiram em participar. Depois desses passos, iniciamos a coleta de dados.

Os sujeitos entrevistados foram escolhidos aleatoriamente. Ressaltamos que, no período em que se deu a entrevista, o programa estava em seu segundo ano e o quadro de professores ministrantes - que, pela natureza do EMMTEC, já seria pequeno, pois os docentes poderiam ministrar componentes curriculares nos três anos do Ensino Médio - estava em tamanho menor, por ainda não abranger a totalidade dessa etapa do ensino básico. Assim, participaram da pesquisa cinco professores, os quais denominamos como P1, P2, P3, P4 e P5, a fim de resguardar suas identidades.

Utilizamos a análise de conteúdo para tratar os dados coletados, dividindo os procedimentos em três fases: pré-análise; exploração do material; tratamento dos resultados, inferência e interpretação. A categorização das respostas foi realizada durante a fase de exploração do material, considerando-se a frequência e a similaridade dos termos presentes nas respostas. As categorias são rubricas ou classes que aglomeram um grupo de elementos que possuem características comuns, sob um título genérico (BARDIN, 2011). 
Na próxima seção, apresentamos as questões da entrevista, os dados obtidos e as categorias geradas a partir deles.

\section{FORMAÇÃO METODOLÓGICA - ANÁLISE DE DADOS}

Expomos, nesta seção, as indagações realizadas na entrevista semiestruturada acerca dos aspectos metodológicos da formação docente ofertada pela SEDUC-RO para o trabalho no EMMTEC, as categorias geradas e a transcrição das respostas.

A primeira indagação foi: a formação ofertada pelo EMMTEC envolve a metodologia que o professor deverá utilizar no desenvolvimento de suas aulas? A partir das respostas para essa questão foi gerada a Categoria I formação voltada para o desempenho em um estúdio, considerando-se as seguintes falas dos participantes:

[...] Então, assim, a formação que a gente teve para entrar em estúdio foi de uma semana e a gente pegou as coisas básicas, e isso foi muito importante para a gente poder já ter... vislumbrar aquilo que nos aguardava, mas a prática pedagógica do como fazer, do como atuar, do como interagir com o aluno é algo que a gente vai criando todos os dias (P1).

[...] o que a gente aprendeu foi a questão do estúdio, de como a gente deve se portar em frente das câmeras, não é como eu fazer em relação à minha disciplina de Sociologia, como eu me portar em frente das câmeras, como trazer o aluno para dentro da aula, tentar envolver o aluno sempre na aula, se eu fizer uma discussão, sempre trazer o aluno... Então é mais nesse sentido (P2).

[...] é só postura de estúdio. A metodologia, que a gente vai entrar, que a gente vai desenvolver nas aulas, é uma coisa combinada entre as pedagogas, né, que são supervisoras, e o professor, os dois professores (P3).

[...] porque é uma empresa de jornalismo, telecomunicação, então, foi sim, mas mais as questões técnicas, assim (P4).

[...] foi orientada a postura diante das câmeras, como focar, como olhar, como falar, né?! A linguagem que deve ser feita, as roupas que devem vestir, os paramentos, né, enfim... Para poder então ficar bem na imagem [...] (P5).

Essas respostas evidenciam que o curso de formação ofertado pela SEDUC-RO para os professores ministrantes do EMMTEC, no que concerne o 
aspecto metodológico, contempla apenas as questões sobre o estúdio de gravação das aulas. A afirmação do P4 de que a formação é realizada por "[...] uma empresa de jornalismo, telecomunicação" salienta ainda mais essa característica do curso de formação.

Uma das funções dos professores ministrantes é dar aulas, que são transmitidas ao vivo para as escolas, ao mesmo tempo em que são gravadas para serem disponibilizadas na internet. Essa dinâmica impossibilita que haja cortes e edição dos vídeos para a correção de eventuais equívocos cometidos pelos professores antes da exibição para os alunos. Desse modo, consideramos que os professores ministrantes realmente necessitam de formação sobre as questões de postura, movimento, entonação de voz, vestimentas, uso de microfone e desempenho em um estúdio de gravação. Contudo, as características do EMMTEC, tais como a separação geográfica entre professores e alunos durante as aulas, a presença de docentes nas escolas receptoras para o auxílio nos processos de ensino e aprendizagem (professores presenciais) e o uso de recursos como a transmissão via satélite e o Ambiente Virtual de Aprendizagem (AVA) para a realização das aulas, não possibilita a distinção do programa do ensino a distância.

Compreendemos que a formação metodológica necessita ir além do preparo para a atuação em estúdio; é necessário o planejamento de aula mediada, o preparo do material didático, a interação e comunicação com os alunos, como a própria SEDUC-RO prevê no curso de formação contido no projeto do EMMTEC. Esses pontos não foram sequer mencionados pelos entrevistados.

Kenski (2012) critica a qualidade didática dos programas comercializados como pacotes pedagógicos, introduzidos em diversos níveis de ensino, e compreende que parte da responsabilidade está nos educadores, que aceitam esses pacotes sem objeções. Como forma de solucionar esse problema, a autora sugere uma formação de professores com base científica e pedagógica que thes proporcione condições para serem produtores, operadores e críticos da educação mediada por tecnologia. 
Do mesmo modo, a formação continuada, na perspectiva críticoreflexiva, fica prejudicada, pois a análise crítica sobre o que foi realizado deve estar relacionada com o aporte teórico, para que haja uma ressignificação da prática. Pimenta (2002, p. 24) explica que:

[...] a teoria tem importância fundamental na formação dos docentes, pois data os sujeitos de variados pontos de vista para uma ação contextualizada, oferecendo perspectivas de análise para que os professores compreendam os contextos históricos, sociais, culturais, organizacionais e de si próprios como profissionais.

A formação metodológica ofertada pela SEDUC-RO foi centrada no estúdio de gravação e sem aprofundamento sobre as bases teóricas da EaD, o que, consequentemente, dificulta a relação teoria-prática e a reflexão crítica sobre ambas.

Prosseguimos a análise dos dados com as respostas para a segunda indagação: qual o tipo de metodologia orientada no processo de formação? As respostas obtidas (de apenas dois participantes) forneceram dados para a criação da Categoria II - metodologia voltada para atuar em estúdio:

[...] mas com relação a questão pedagógica, não, até porque quem deu a formação foi uma menina jornalista e era mais no sentido da gente, por exemplo, é... como falar com as câmeras, como se comportar meio que dentro do estúdio, que roupa usar, entendeu $(\mathrm{P} 1)$ ?

Postural, apresentação pessoal, comportamento (P4).

Embora apenas dois professores ( $\mathrm{Pl}$ e $\mathrm{P} 4)$ tenham respondido à questão proposta, ambas as respostas corroboraram as recebidas na questão I, sobre a formação ofertada pela SEDUC-RO ter sido voltada para a atuação do professor no estúdio de gravação das aulas. Entre os demais participantes, dois professores disseram que não houve curso de formação para o aspecto metodológico e um professor disse que já havia respondido a questão II juntamente com a questão I, confirmando que a formação ofertada foi sobre o desempenho do professor no estúdio de gravação.

As atribuições do professor ministrante descritas no projeto do EMMTEC, anteriormente apresentadas neste artigo, evidenciam a grande demanda 
de trabalho e de competências para desenvolvê-lo. Contudo, ao longo do texto do projeto, percebemos que a elaboração do Plano de Estudo para a recuperação paralela é desenvolvida conforme as necessidades apontadas pelo professor presencial. Considerando-se o número de escolas polo e alunos atendidos, as demandas podem ser bem variadas, requerendo que o docente tenha acuidade para a produção desse instrumento.

O projeto também assegura que "os alunos utilizarão os livros fornecidos pela SEDUC e o material de apoio produzido pelos professores ministrantes" (RONDÔNIA, 2016, p. 58). Logo, apesar de não elencado, o desenvolvimento de material didático para auxílio nos processos de ensino e aprendizagem é também atribuição do professor ministrante. Contudo, nas respostas dos entrevistados, não há referência sobre formação para a execução dessa atividade.

Kenski (2012) nos alerta para a diversidade de conhecimentos requeridos pelo ensino mediado por tecnologia, fator que pudemos observar no EMMTEC. Kenski (2012, p. 64) afirma que "a linguagem em que é estruturado o hipertexto não pode ser formal, nem informal". Nesse sentido, o desenvolvimento de hipertextos, assim como a reflexão sobre o processo de ensino com mediação tecnológica para a assunção de novas perspectivas filosóficas - de modo a aproveitar as possibilidades de comunicação e informação das novas tecnologias - são pontuados pela autora, mas estão ausentes nas falas dos sujeitos da pesquisa.

Nessa mesma perspectiva, Pallof e Pratt (2015, p. 15) dizem que "o ensino e a aprendizagem por meio do uso da tecnologia exigem mais que o domínio de um software, embora esse continue a ser o foco do treinamento de professores". Então, os professores precisam desenvolver a consciência do impacto que a aprendizagem on-line possui sobre o próprio processo de ensino e aprendizagem, para que possam fazer a transição da modalidade presencial para a EaD de modo bem-sucedido.

Devemos salientar que, de acordo com o perfil delineado dos sujeitos deste estudo, O EMMTEC é a primeira experiência de todos com o ensino por mediação tecnológica. Assim sendo, trabalhar os aspectos metodológicos 
para o ensino nessa modalidade é fundamental para a formação dos professores. Outrossim, verificamos que a capacitação prevista no projeto, denominada Didática no Ensino Presencial Mediado, não foi a mesma ofertada para os professores ministrantes, haja vista que os aspectos didático-metodológicos não foram relatados pelos entrevistados.

Dessa maneira, entendemos que a formação centrada na escola, assim como a prática reflexiva, é prejudicada, pois deve-se privilegiar o contexto escolar e as necessidades notadas pelos profissionais que nela atuam, conforme vemos nos apontamentos de Imbernón (2010, p.85):

A formação centrada na escola envolve todas as estratégias empregadas conjuntamente pelos formadores e pelos professores para dirigir os programas de formação de modo a que respondam às necessidades definidas da escola e para elevar a qualidade do ensino e da aprendizagem em sala de aula e nas escolas.

Consideramos, portanto, que a formação dos professores ministrantes para o EMMTEC contempla apenas parte do contexto envolvido, pois as questões metodológicas são trabalhadas parcialmente por agentes externos, enquanto os demais fatores que compõem o trabalho do professor no ensino com mediação tecnológica não são abordados.

\section{CONSIDERAÇÕES FINAIS}

O projeto EMMTEC visa atender ao alunado do campo com o uso de tecnologias para mediar os processos de ensino e aprendizagem. Esse objetivo constitui, por si só, a relevância social de estudos desenvolvidos sobre questões como a formação de professores ministrantes e presenciais, o impacto do programa e o desempenho dos alunos. Entretanto, o aprofundamento teórico realizado para a materialização desta pesquisa demonstrou a dificuldade de encontrar estudos sobre a formação de professores para o ensino com mediação tecnológica, mesmo havendo programas similares ao EMMTEC em funcionamento há uma década.

A raridade de investigações sobre esse objeto nos levou a questionar a importância dada para a formação de docentes que trabalham nessa 
modalidade. Assim, entendemos que a investigação aqui desenvolvida possui relevância social e científica, servindo para o desenvolvimento de novos estudos acerca do objeto.

A importância da formação para a mediação tecnológica pode ser verificada por meio das peculiaridades e demandas dessa forma de ensino. Os indicadores apresentados neste estudo, entretanto, apontam que a formação de professores ministrantes ofertada pela SEDUC-RO não está em total conformidade com a que consta no projeto do EMMTEC, a começar pela carga horária: são previstas 80 horas para a formação e, na realidade, foram realizadas apenas 40 horas. Um dos participantes revelou ter começado a trabalhar no EMMTEC antes de realizar o curso de formação, substituindo um docente que desistiu do cargo no decorrer do ano letivo; então, como o curso de formação já se havia encerrado, o professor foi aprendendo a "fazer fazendo" e, somente no ano seguinte, o referido professor fez a formação com outra turma de docentes.

Entendemos, também, que a contratação de uma equipe de jornalismo para auxiliar na formação dos professores ministrantes demonstra o cuidado com o qual a SEDUC-RO tem lidado com a transmissão das aulas e o comportamento dos professores frente às câmeras. Assistimos a algumas aulas do EMMTEC disponibilizadas na internet e verificamos a dinâmica dos professores frente às câmeras, o uso de linguagem e entonação de voz, trajes alusivos aos componentes curriculares trabalhados, o emprego de imagens, cores e formas na apresentação dos conteúdos. Tudo isso, de fato, contribui para chamar a atenção do espectador. Esses pontos foram relatados pelos sujeitos como fatores explorados na formação realizada.

Ponderamos, entretanto, que os aspectos metodológicos estão além da atuação do professor no estúdio de gravação. A literatura nos mostrou que a utilização das $\mathrm{TIC}$ requer do professor práticas de ensino diferenciadas, para que haja significância nos processos de ensino e aprendizagem. As respostas dos entrevistados nos mostraram que apenas o trabalho do professor nos estúdios foi considerado como fator metodológico no curso de formação, faltando trabalhar o planejamento de aulas, a elaboração de 
material didático, a seleção e produção de recursos comunicativos, a contextualização, a transdisciplinaridade e a vivência na sala de aula mediada por tecnologias, como está previsto no projeto.

Ao caminharmos para o final deste estudo, novos questionamentos surgiram e aqui são apontados como sugestões para futuras pesquisas: (i) a formação dada aos professores ministrantes do EMMTEC envolveu os aspectos de diversidade culturalę; (ii) em comparação com os demais programas de mediação tecnológica no país, como ocorre o desempenho do professor ministrante no estúdio?; (iii) como é a mediação pedagógica do professor ministrante no AVA?; (iv) houve formação para os professores presenciais do EMMTEC? Se sim, em quais aspectos?

\section{REFERÊNCIAS}

AZEVEDO, H. J. S. de. Tecnologias da Informação e Comunicação na educação: considerações a partir do conceito de "contradição" da teoria da atividade humana. In: CORTELAZZO, I. B. de C. (Org). Docência em ambientes de aprendizagem online. Salvador: EDUFBA, 2009.

BARDIN, L. Análise de conteúdo. São Paulo: Edições 70, 2011.

BOGDAN, R. C.; BIKLEN, S. K. Investigação qualitativa em educação: uma introdução à teoria e aos métodos. Porto: Editora Porto, 1994.

CANDAU, V. M. Formação continuada de professores: tendências atuais. In: CANDAU, V. M. (Org.). Magistério: construção cotidiana. $4^{a}$ ed. Petrópolis: Vozes, 2001, p.51-68.

CARVALHO, M. C. A. de; DAMASCENO, E. A.; MOURA, M. do S. L. Navegando em águas turvas no campo da política e da formação de professores. Revista Exitus, [S. I.], v. 9, n. 3, p. 169-196, 2019. DOI: 10.24065/2237-9460.2019v9n3ID940. Disponível em: <http://www.ufopa.edu.br/portaldeperiodicos/index.php/revistaexitus/article /view/940>. Acesso em: 14 fev. 2021.

IMBERNÓN, F. Formação continuada de professores. Porto Alegre: Artmed, 2010.

KENSKI, V. M. Educação e tecnologias: o novo ritmo da informação. $4^{a}$ ed. Campinas: Papirus. 2008. 
KENSKI, V. M. Tecnologias e ensino presencial e a distância. $9^{a}$ ed. Campinas: Papirus, 2012.

LIBÂNEO, J. C. Profissão professor ou adeus professor, adeus professora? Exigências educacionais contemporâneas e novas atitudes docentes. $10^{a}$ ed. São Paulo: Cortez, 2007.

LÜDKE, M.; ANDRÈ, M. A pesquisa em educação: abordagens qualitativas. São Paulo: EPU, 1986.

PALLOF, R. M.; PRATT, K. Lições da sala de aula virtual: as realidades do ensino on-line. $2^{a}$ ed. Porto Alegre: Penso, 2015.

PIMENTA, S. G. Professor reflexivo: construindo uma crítica. In: PIMENTA, S. G.; GHEDIN, E. (Orgs.). Professor reflexivo no Brasil: gênese e crítica de um conceito. São Paulo: Cortez, 2002, p. 17-47.

RONDÔNIA. Secretaria de Estado de Educação de Rondônia. Projeto de ensino médio com mediação tecnológica. Porto Velho: SEDUC-RO, 2016.

SCHÖN, D. A. Educando o profissional reflexivo: um novo design para o ensino e a aprendizagem. Porto Alegre: Artmed, 2000.

TARDIFF, M. Saberes docentes e formação profissional. $13^{a}$ ed. Petrópolis: Vozes, 2012.

Recebido em: 19 de julho de 2021. Aprovado em: 22 de outubro de 2021. Publicado em: 20 de novembro de 2021. 